\title{
SIMULATION OF STRONG GROUND MOTIONS
}

\author{
By David M. Hadley and Donald V. Helmberger
}

\begin{abstract}
The estimation of potential strong ground motions at short epicentral distances ( $\Delta=10$ to $25 \mathrm{~km}$ ) resulting from large earthquakes, $M \geqq 6.5$, generally requires extrapolation of a limited data set. The goal of this project has been to quantify the extrapolation through a simulation technique that relies heavily upon the more extensive data set from smaller magnitude earthquakes. The simulation utilizes the smaller events as Green's functions for the elements of a larger fault. Comparison of the simulated peak acceleration and duration with the data from the Parkfield earthquake is very good. Simulation of three earthquakes, $M=5.5,6.5$, and 7.0 indicate that the slope of the peak acceleration versus distance curve ( $\Delta=5$ to $25 \mathrm{~km}$ ) flattens, for strike-slip earthquakes, as the magnitude increases.
\end{abstract}

\section{INTRODUCTION}

Very few strong-motion records from large earthquakes at small hypocentral distance currently exist. Indeed, most of the data have been recorded at hypocentral distances greater than 20 to $25 \mathrm{~km}$. The extrapolation of this data set to small distances has been necessarily guided by simple physical considerations and intuition. As a result, the form of the extrapolation is subject to the personal bias of individual investigators. The goal of this project has been to quantify the extrapolation through a careful simulation technique that relies heavily upon the more extensive data set from smaller magnitude earthquakes. The simulation is guided by generally accepted aspects of computational seismology.

The seismogram recorded by a strong-motion accelerograph is the result of the physical interaction of many complex processes. As the rupture front passes a point on the fault, each particle accelerates, reaches some peak velocity, and finally slows to a stop. The magnitude of the acceleration is controlled by the tectonic stress in the region around the fault and by the frictional stress on the fault surface. The effective stress, $\sigma_{e}$, acting to accelerate each particle, is the difference between these two stresses. As each particle accelerates, it radiates seismic energy. Before this elastic energy is recorded at the station, it is filtered in several significant ways. The energy is absorbed by anelastic wave propagation and scattered by random heterogeneities. Purely elastic propagation through the earth filters the signal (e.g., Helmberger and Malone, 1975; Heaton and Helmberger, 1978). Finally, interaction with the surface of the Earth results in further distortions. Each physical process can be represented by a filter or operator. The final signal is then the convolution of each operation that transfers energy from the particle to the station. The generation of synthetic seismograms has been extremely important in understanding the seismic source and in defining the details of the Earth's structure (e.g., Burdick, 1977; Langston, 1978). The operators describing the seismic source, attenuation, and wave propagation can be computed analytically or derived empirically. Provided the various operators are known in sufficient detail, the generation of synthetic time histories is fairly straightforward.

In a recent study of the 1940 Imperial Valley earthquake, Hartzell (1978a), found that the main-shock seismogram recorded at El Centro could be simulated by the 
superposition of several of the major aftershocks. Physically, this simulation is very attractive. The record for each aftershock is the cumulative result, for a portion of the fault, of all physical processes discussed above. To simulate the main shock requires only fairly simple scaling for moment. The lag time for the superposition of each aftershock record is determined by the progression of the rupture front. Kanamori (1978) has carried this technique further by using regional records from the $M=6.4$ Borrego Mountain earthquake to simulate rupture along the San Andreas for a $M=8$ earthquake. Since the Borrego Mountain records were not recorded over the full range of distances and azimuths that would be required to perfectly simulate ground motion in Los Angeles, some scaling of the observed records was necessary. In particular, as the observed records were primarily surface waves, amplitudes were scaled for distance by $r^{-1 / 2}$. Finally, the amplitudes were corrected for radiation pattern and the scaled observed records were lagged in time to simulate the rupture process.

The utilization of small earthquakes to simulate large events can expand significantly the usefulness of the large number of accelerograms from smaller events $\left(M_{L} \sim 4.5\right.$ to 5.5$)$. In the following sections we discuss first the data set available for the simulation of large strike-slip earthquakes at small epicentral distances. As a test of the technique, we simulate the Parkfield earthquake and compare the results with the observations. Next we discuss the simulation of three earthquakes $M \sim 5.5$, 6.5 , and 7.0 at epicentral distances ranging from 5 to $25 \mathrm{~km}$. Finally, we compare the attenuation scaling for peak acceleration with the observations from seven $M \sim 6.5$ earthquakes recorded at larger distances.

\section{Empirical Green's Functions}

Within this study we will restrict the simulation to the fairly simple geometry of a strike-slip earthquake. We therefore require accelerograms from $M=4.5$ to 5.5 earthquakes recorded over a distance range of about 5 to $30 \mathrm{~km}$. The computer algorithm used to superpose the observational Green's functions is easily implemented if all records are obtained from earthquakes with about the same moment. If several different earthquakes are necessary to fulfill the distance requirement then some care must be exercised in either scaling the raw data for moment $\left(M_{0}\right)$ or adjusting the effective fault area in the simulation to correspond with each observation.

The data set used in this study comes from a $M_{L}=4.8$ earthquake that was well recorded at six stations ranging in epicentral distance from 5.7 to $33.4 \mathrm{~km}$ (Figure 1). The event was a strike-slip, occurred at a depth of $12 \mathrm{~km}$, and was located in the Horse Canyon area of the Southern California Peninsular Ranges. A surface-wave investigation by Kanamori (1976) shows that the moment of this event was $3 \times 10^{23}$ dyne $\mathrm{cm}$. A study by Hartzell (1978b) further supports this moment estimate and, in addition, shows that the event was very impulsive. The far-field displacement pulse recorded at station Anza Post Office was well modeled by Hartzell with a trapezoidal time function with a width of $150 \mathrm{msec}$. The corrected accelerograms for the six stations shown in Figure 1, are shown in Figure 2. The first four stations are located on hard rock or on very thin sediments overlying a granitic or metamorphic complex. Stations Rancho Anza and Clark Lake are situated on sediments. Ideally, all accelerograms used in the simulation should be recorded on the same site conditions. Because of the site bias, the resulting simulations are most appropriate for hard or stiff site conditions. The careful placement and orientation of each strong motion instrument with respect to the San Jacinto fault zone has resulted in each 
horizontal component being very nearly naturally rotated into either $S V$ (radial component) or $S H$ (transverse component).

Within the simulation calculations discussed below, the radiation pattern modulation of the observed amplitudes is explicitly included. Hence, it is necessary to increase the amplitudes in order to recover the original source strength. Table 1 shows the expected modulation of the signal at each station that should result from the product of the horizontal and vertical radiation pattern. Also, included in this

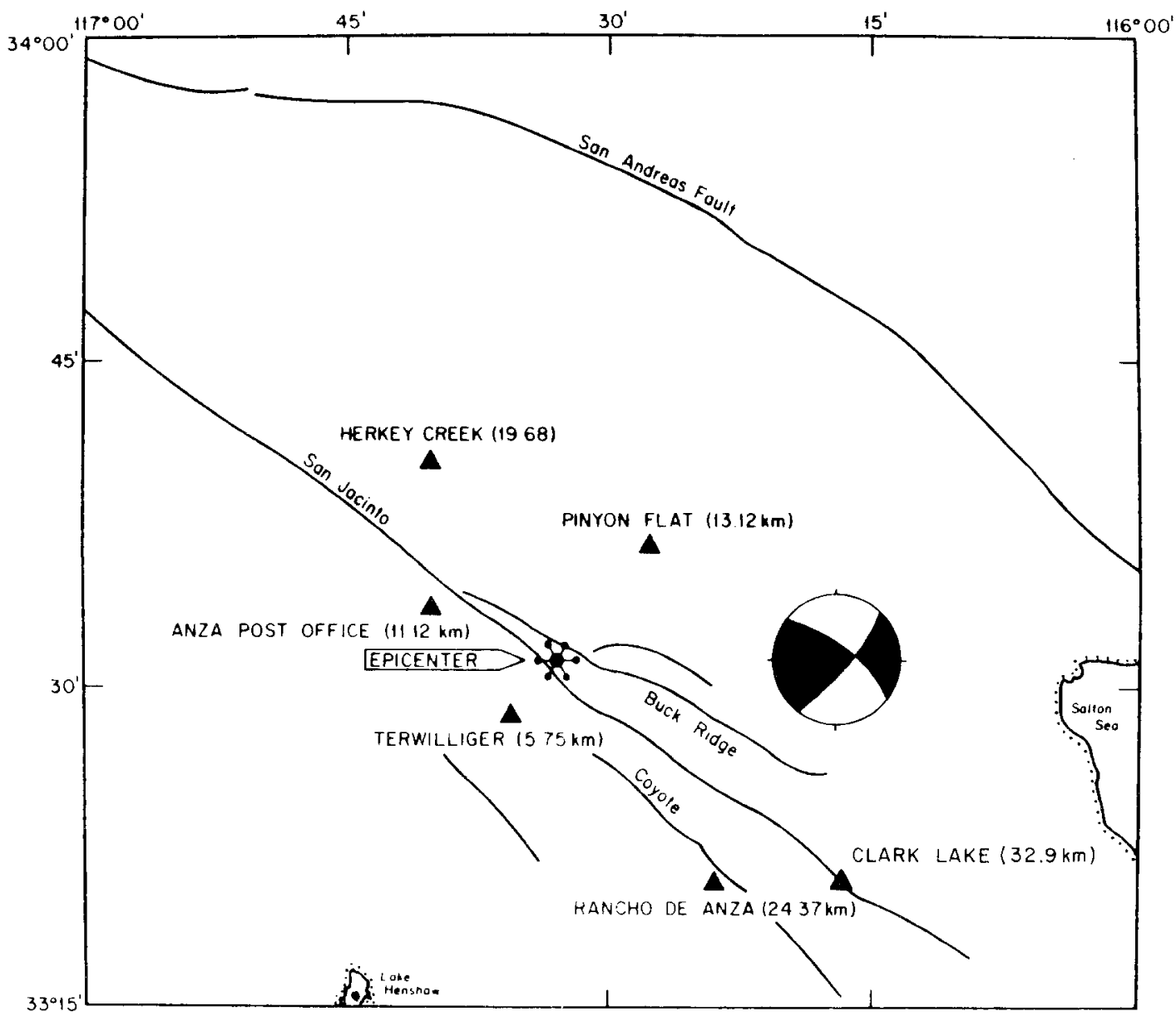

FiG. 1. Epicenter, focal mechanism, and strong-motion array that recorded the August $1975, M_{L}=4.8$ earthquake (after Hartzell, 1978).

table is the observed amplitude of the $S$-wave velocity pulse derived from integration of the accelerograms. From Figure 1 it is clear that several $S V$ arrivals are very close to nodal. However, from Figure 2 it is equally clear that the $S V$ traces have relatively large amplitudes. This observation contradicts the assumption that the focal mechanism absolutely dominates the observed amplitudes. Within southern California, focal mechanism studies are frequently carried out using the regional array. The frequency content of the recorded signals is comparable to the Horse Canyon earthquake and reliable focal mechanisms are regularly computed. However, it is typically observed that near a node of a focal mechanism, apparent polarity errors are frequently encountered. In a heterogeneous earth, minor deviations from the straight line travel path are expected. Hence, perfect nodes are most unlikely. Using 
the experience from the focal mechanism studies, we have restricted the amplitude variation in the radiation pattern to the range $\{1$ to 0.2$\}$. This restriction has been used in both correcting the data and in the simulation. This approximation is equivalent to the assumption that the observed record is never closer than about<smiles>[SbH]</smiles>

89.9

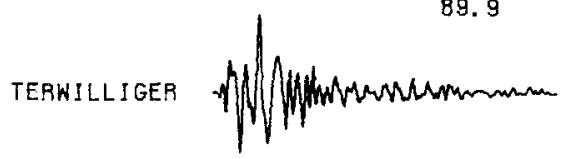

138. 0

ANZA POST

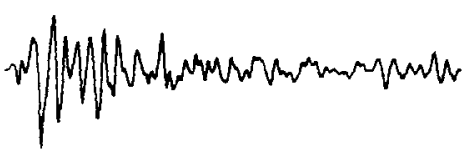

54.9

PINTON FLATS

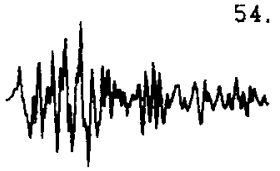

45. 7

HURKEY С̈EEK

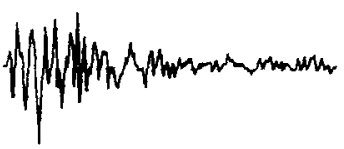

95.1

RANCHO ANZA

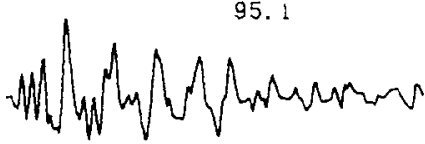

45. 2

CLARK LAKE

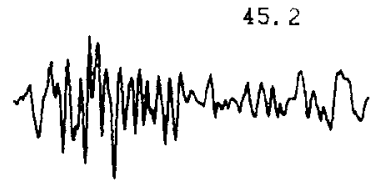

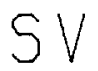

47.2

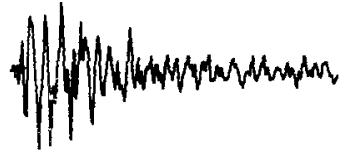

124.9

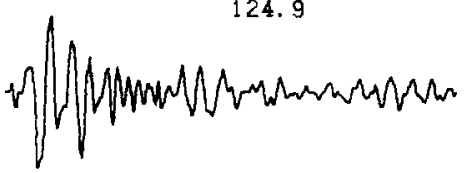

64.1

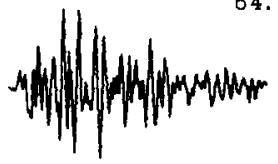

77.1

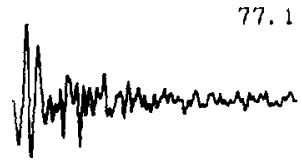

104.0

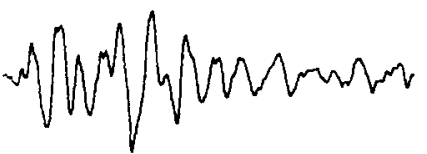

43. 4

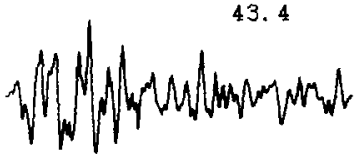

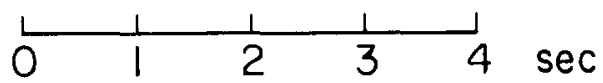

FIG. 2. Accelerograms recorded from the Horse Canyon earthquake. The numbers are peak acceleration in $\mathrm{cm} / \mathrm{sec}^{2}$.

$10^{\circ}$ to a node. This assumption has two effects on the following calculations. (1) Because of the station geometry, the restriction to a minimum radiation correction of 0.2 (corrected amplitude $=$ observed/0.2) effects only the $S V$ observations. As shown in Table 1 , the corrected $S V$ amplitudes for each station are consistently larger than $S H$, whereas the source strength should be the same. Hence the accelerograms corrected for the radiation pattern and use in the following simula- 
tions may be slightly too large for the moment and magnitude of the earthquake. (2) By restricting the radiation pattern to a minimum of 0.2 , all segments of the fault will radiate in the simulation discussed below. Without this assumption, portions of the fault would not contribute to the simulated record. Hence, the assumption of a restricted radiation pattern results in a slight overestimation of the source strength and in a fault simulation that radiates more energy toward the station.

TABLE 1

CORRECTION OF THE OBSERVED $S H$ AND $S V^{*}$

\begin{tabular}{lccccccc}
\hline \multicolumn{1}{c}{ Station } & $R$ & $\phi_{S H}$ & $\phi_{S V}$ & $V_{S H}$ & $V_{S V}$ & $V_{S H / \phi_{S H}}$ & $V_{S V_{/, \phi_{V}}}$ \\
\hline Terwilliger & 13.3 & 0.43 & $0.2 \dagger$ & 1.73 & 1.19 & 4.02 & 5.95 \\
Anza & 16.3 & 0.56 & 0.38 & 4.03 & 3.33 & 7.20 & 8.76 \\
Pinyon & 17.8 & 0.72 & $0.2 \dagger$ & 1.18 & 0.43 & 1.64 & 2.15 \\
Herkey & 23.0 & 0.69 & 0.50 & 0.62 & 0.78 & 0.90 & 1.56 \\
Rancho & 27.2 & 0.78 & 0.45 & 1.52 & 2.27 & 1.95 & 5.04 \\
Clark & 33.5 & 0.92 & $0.2 \dagger$ & 0.37 & 0.64 & 0.40 & 3.20 \\
\hline
\end{tabular}

* Velocity pulses corrected for radiation pattern. $R$ is hypocentral distance, $\phi$ is the product of the horizontal and vertical radiation pattern, and $V$ is the observed amplitude of the $S$-wave pulse.

$\dagger$ As discussed in the text, the radiation pattern has been restricted to the range (1 to 0.2 ).

TABLE 2

Normalized Peak Displacement Versus Hypocentral Distance

\begin{tabular}{|c|c|c|c|c|c|c|}
\hline Event & Date & $M_{L}$ & $\begin{array}{c}\text { Max Amp. } \\
(\mu)\end{array}$ & $\begin{array}{l}\text { Corr. Amp. } \\
\qquad(A \mu)\end{array}$ & $R$ & $R^{*} A^{*} 10^{-3}$ \\
\hline 1 & $10 / 27 / 69^{*}$ & 4.6 & 2918 & 5070 & 13.6 & 68.9 \\
\hline 2 & $3 / 13 / 70$ & 4.7 & 751 & 990 & 14.7 & 14.6 \\
\hline $3 a$ & $12 / 29 / 71$ & 4.0 & 144 & 1313 & 13.7 & 18.0 \\
\hline $3 \mathrm{c}$ & $12 / 29 / 71$ & 3.7 & 90 & 1880 & 12.8 & 24.1 \\
\hline $4 A$ & $2 / 24 / 72$ & 5.1 & 1242 & 542 & 30.4 & 16.5 \\
\hline $4 \mathrm{E}$ & $2 / 24 / 72$ & 3.6 & 21 & 578 & 26.7 & 15.4 \\
\hline 5 & $2 / 27 / 72$ & 4.7 & 158 & 208 & 40.7 & 8.5 \\
\hline 6 & $10 / 4 / 72$ & 4.7 & 624 & 822 & 21.9 & 18.0 \\
\hline Station 2 & $6 / 27 / 66^{\dagger}$ & 5.65 & 220000 & 21000 & 1 & 21 \\
\hline Station 5 & $6 / 27 / 66$ & 5.65 & 53000 & 5000 & 5 & 25 \\
\hline Station 8 & $6 / 27 / 66$ & 5.65 & 43000 & 4100 & 9 & 37 \\
\hline Station 12 & $6 / 27 / 66$ & 5.65 & 30000 & 2900 & 14 & 40.6 \\
\hline Temblor & $6 / 27 / 66$ & 5.65 & 46000 & 4400 & 10.4 & 46 \\
\hline Terwilliger & $8 / 2 / 75$ & 4.8 & 850 & 850 & 13.3 & 11.3 \\
\hline Ansa P. $O$. & $8 / 2 / 75$ & 4.8 & 2280 & 2280 & 16.3 & 37.2 \\
\hline Pinyon Flat & $8 / 2 / 75$ & 4.8 & 990 & 990 & 17.8 & 17.6 \\
\hline Hurkey Cr. & $8 / 2 / 75$ & 4.8 & 963 & 963 & 23.1 & 22.2 \\
\hline Rancho & $8 / 2 / 75$ & 4.8 & 2900 & 2900 & 27.2 & 78.5 \\
\hline \multirow[t]{2}{*}{ Clark } & $8 / 2 / 75$ & 4.8 & 940 & 940 & 33.5 & 31.5 \\
\hline & & & & & & $x=29$ \\
\hline
\end{tabular}

* Events 1 to 6 (Johnson and McEvilly, 1974).

$\dagger$ Parkfield, $M=5.5$ (Berkeley), 5.8 (Pasadena); $R$ is taken as shortest distance to rupture surface.

Table 2 compares the maximum displacement pulse at each station for the Horse Canyon earthquake with strike-slip events recorded in central California. Since the direct $S$-wave is, in general, the largest arrival on these records, we have corrected the observed amplitudes by the shortest distance to the rupture surface $(1 / R)$. Events 1 to 6 have been studied extensively by Johnson and McEvilly (1974). We have used their moment-magnitude relation to correct the amplitudes to a $M_{L}=4.8$ 
earthquake (log $M_{0} \sim 1.2 M_{L}$, amplitude $\sim$ moment). With a typical uncertainty in the magnitudes of 0.1 to 0.2 , we would expect about a factor of two scatter in the observed corrected maximum displacement amplitudes. The overall average amplitude, Table 2, is in good agreement with the Horse Canyon data. This comparison shows that the maximum Horse Canyon displacements are compatible with the experience from other earthquakes in various locales. We conclude from this comparison that the Horse Canyon event is not an anomalous earthquake.

\section{Simulation}

Conceptually, the simulation of a large earthquake through the superposition of many small events is fairly simple. The required computer code has to contain a grid for the large fault. The area of each grid element should be comparable to the fault area associated with the observed records used in the simulation. For the Horse Canyon data set, with a rupture velocity near the $S$-wave velocity, and assuming a bilateral rupture, the observed source-time function width of $150 \mathrm{msec}$

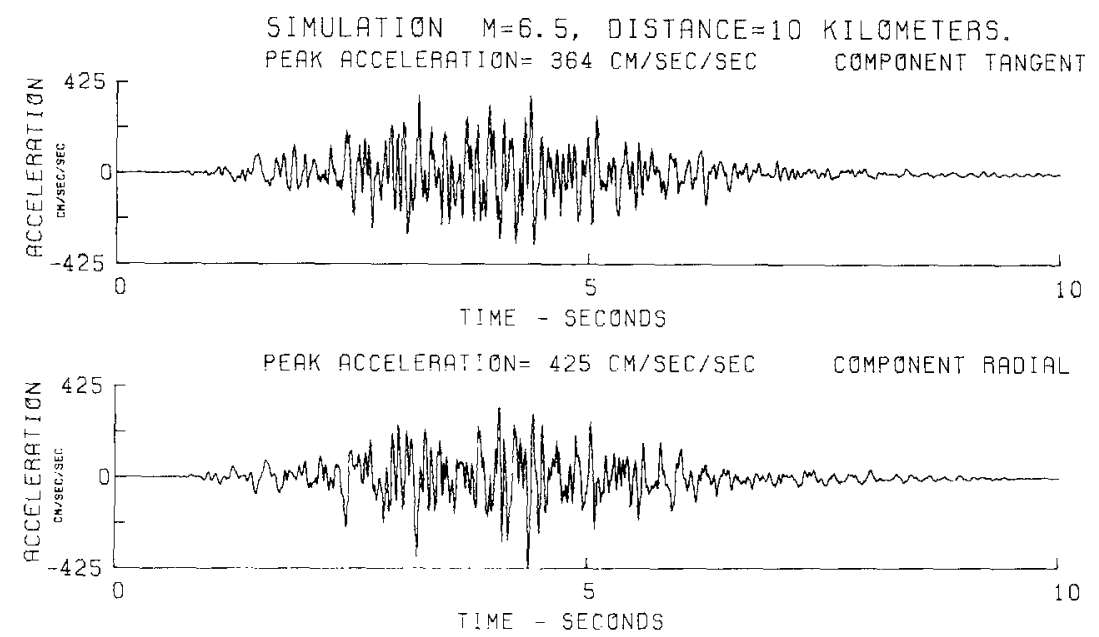

FIG. 3. Simulation for magnitude 6.5 earthquake at an epicentral distance of $10 \mathrm{~km}$. The fault geometry and moment release are adopted from the Borrego Mountain earthquake.

(Hartzell, 1978b) suggests an element size of about $1.2 \mathrm{~km}$. For each element, the hypocentral distance to the station is next calculated. The observed accelerogram with a hypocentral distance most similar to the element is selected for use in the superposition. The amplitudes of the normalized accelerograms are scaled for horizontal and vertical radiation pattern and for distance. Finally, at a time appropriate to simulate fault rupture and $S$-wave propagation from the element to the station, the scaled records $(S V$ and $S H$ ) are rotated into components parallel (transverse) and perpendicular (radial) to the fault and summed. A very typical example of the simulated records is shown in Figure 3. In this example, the fault geometry is taken from the Borrego Mountain earthquake. Rupture is toward the station and the station is located $10 \mathrm{~km}$ perpendicular from the end of the simulated fault.

In order for the simulations, such as that shown in Figure 4, to be optimally useful for engineering purposes, care must be exercised in both the rupture characteristics and the scaling of the observed records. For instance, if the rupture propagates uniformally through the grid, then an artificial periodicity will occur (period = grid size/rupture velocity) in the simulation. We have avoided this problem by randomly 
locating a point vertically and horizontally within each grid and calculating turn-on times, travel times, and radiation and distance effects from this point. Amplitude scaling involves both radiation pattern and distance effects. The modulation of the radiation pattern is discussed above. Since the data set is limited, some scaling for distances is required. Two different techniques have been tested. First, an average source strength was chosen by fitting a curve of the form $r^{-x}$ ( $r$ is hypocentral distance) through the observed peak velocity values, corrected for radiation pattern. In the simulation, the source amplitude of the appropriate records for each element was scaled by $r^{-x}$. A second technique used a linear interpolation of the observed peak amplitudes between observations. An example of the difference in the average peak acceleration over a range of distances is shown in Figure 4. Each point on the figure is the average of the peak acceleration for four simulations for a Borrego Mountain-size earthquake. In the first two simulations, the stations are located along a line perpendicular to the end of the fault. Rupture proceeds both toward and away from the stations. In the second two simulations, the stations are

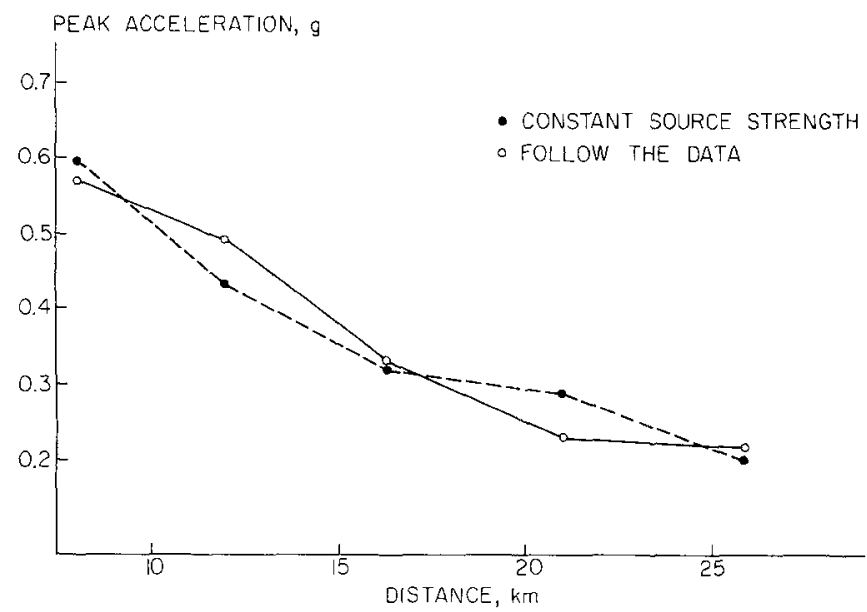

FIG. 4. Comparison of the average peak acceleration for the two cases of scaling the source strength by linear interpolation of the data and by using a constant source strength with distance dependence of the form $r^{-x}$.

located perpendicular to the center of the fault and rupture is first bilateral, initiating from the center of the fault, and then unilateral from one end. The average peak accelerations (Figure 4) show good agreement between these two techniques. In the following simulations we will use the linear interpolation technique. For an occasional element that is slightly outside of the hypocentral data range we will use the constant source strength scaling. Amplitude scaling for variations in the depth of each element is based on the assumption of a simple elastic half-space model. The vertical radiation pattern is computed from the straight-line path connecting the element and the station. If the simulation technique outlined in this paper were to be used for soft-sedimentary site conditions, then the depth dependence should be more explicitly included. A larger suite of accelerograms from a range of source depths would be required to satisfactorily incorporate depth dependence.

A final scaling consideration involves the length of time that each element is active and the moment increment released in each element. Modeling of the Horse Canyon earthquake has demonstrated a very short time function (Hartzell, 1978a). For the case of modeling larger earthquakes, some multiple $A_{0}$, Horse Canyon 
earthquakes may be released in each element in order to simulate the correct moment. If the observed record is simply multiplied by $A_{0}$, then the amplitude of the accelerograms added together in the simulation would scale linearly with displacement (since $D=\frac{1}{2} a t^{2}$, where $D$ is the displacement, $a$ is the acceleration, and $t$ is the length of time the fault is active in the element). In view of the observation that larger earthquakes have longer time functions (Kanamori and Anderson, 1975), the assumption of a constant time function, independent of magnitude, is not supported by any data. Brune (1970) has shown that the displacement time history of a point on the fault is controlled by the effective stress. Kanamori and Anderson (1975) have further shown that the ratio of the characteristic time $\left(\tau_{c}=\right.$ rise time of a point on the fault) to the rupture time, $T_{R}$, is proportional to the effective stress $\left(\tau_{c} / T_{R} \sim \sigma_{e}{ }^{-1}\right)$. We have selected the constant of proportionality from the data discussed in Kanamori and Anderson (1975). The form of our dynamic similarity relationship is $\tau_{c}=T_{R} / 8$. This line passes through the center of the data discussed in Kanamori and Anderson (1975) and is parallel to the results of Aki, 1972.

In order to simply match the two constraints for each element so that it is active for the time $\tau_{\mathrm{c}}$ and releases a moment proportional to $A_{0}$, we have used $N$ events ( $N=\tau_{c}$ /rise time for Horse Canyon), each with an amplitude proportional to $A_{0} / N$. The first source is turned on when the rupture front reaches some random point in the element (see discussion above). The remaining sources are distributed randomly over the time $\tau_{c}$.

We have tested the effect of the dynamic similarity assumption by simulating several earthquakes at a range of distances (independent of rupture time). These numerical experiments have shown that peak acceleration is sensitive to the constant of proportionality in the dynamic similarity condition. The simulation can be crudely thought of as an ensemble of random pulses that closely approximate in amplitude and relative position the physics of the earthquake source and of the wave-propagation effects for the Earth. Hence, if the total energy released observed at an epicentral distance $\Delta$, is confined into a time interval $T\left(\tau_{c}, T_{R}, \Delta\right)$ constructive interference must increase the absolute amplitude as $T$ is decreased. Therefore, before the simulation can be completely used in engineering design decisions, additional constraints, or increased confidence in the dynamic similarity condition, must be established.

Although the absolute level of the peak accelerations are sensitive to the similarity condition (which is also equivalent to changing the rupture velocity), we have found that the relative scaling with hypocentral distance was quite insensitive. As shown in the following section, the grouping in time of the ensemble of pulses that constructively interfere to generate the peak acceleration is sensitive to the faultstation geometry and the moment release. If the rupture velocity/dynamic similarity condition is altered, then the time window over which pulses arrive can be expanded or compressed. The numerical results of this study suggest that the absolute level of the attenuation curves are sensitive to the rupture velocity, but that the shape of the curves are primarily controlled by fault-station geometry. In the verification study of the Parkfield earthquake, discussed in the next section, the simulated peak accelerations are in good agreement with the data for a rupture velocity of $0.9 \beta$.

\section{Trial Simulation: Parkfield}

Five strong-motion stations with distance from the fault ranging from 1 to $14 \mathrm{~km}$ recorded the Parkfield earthquake of June 28, 1966. This earthquake has a surface- 
wave magnitude of $M_{S}=6.4$, and a local magnitude, $M_{L}=5.5$ to 5.8 (Berkeley and Pasadena, respectively). This event has been well-studied by many investigators. We adopt a moment of $3.8 \times 10^{25}$ dyne-cm and fault dimension of $31 \times 9 \mathrm{~km}$. These values are intermediate between those of Tsai and Aki (1969), Scholz et al. (1969), Eaton et al. (1970), and Trifunac and Udwadia (1974). Following the above investigators, we have allowed the fault to rupture toward station 2 (horizontal distance to the fault surface $=1 \mathrm{~km}$ ). We have adopted a rupture velocity that is 0.9 of the shear-wave velocity. Varying the rupture velocity is identical to changing the dynamic similarity condition discussed above. Within this simulation we will be

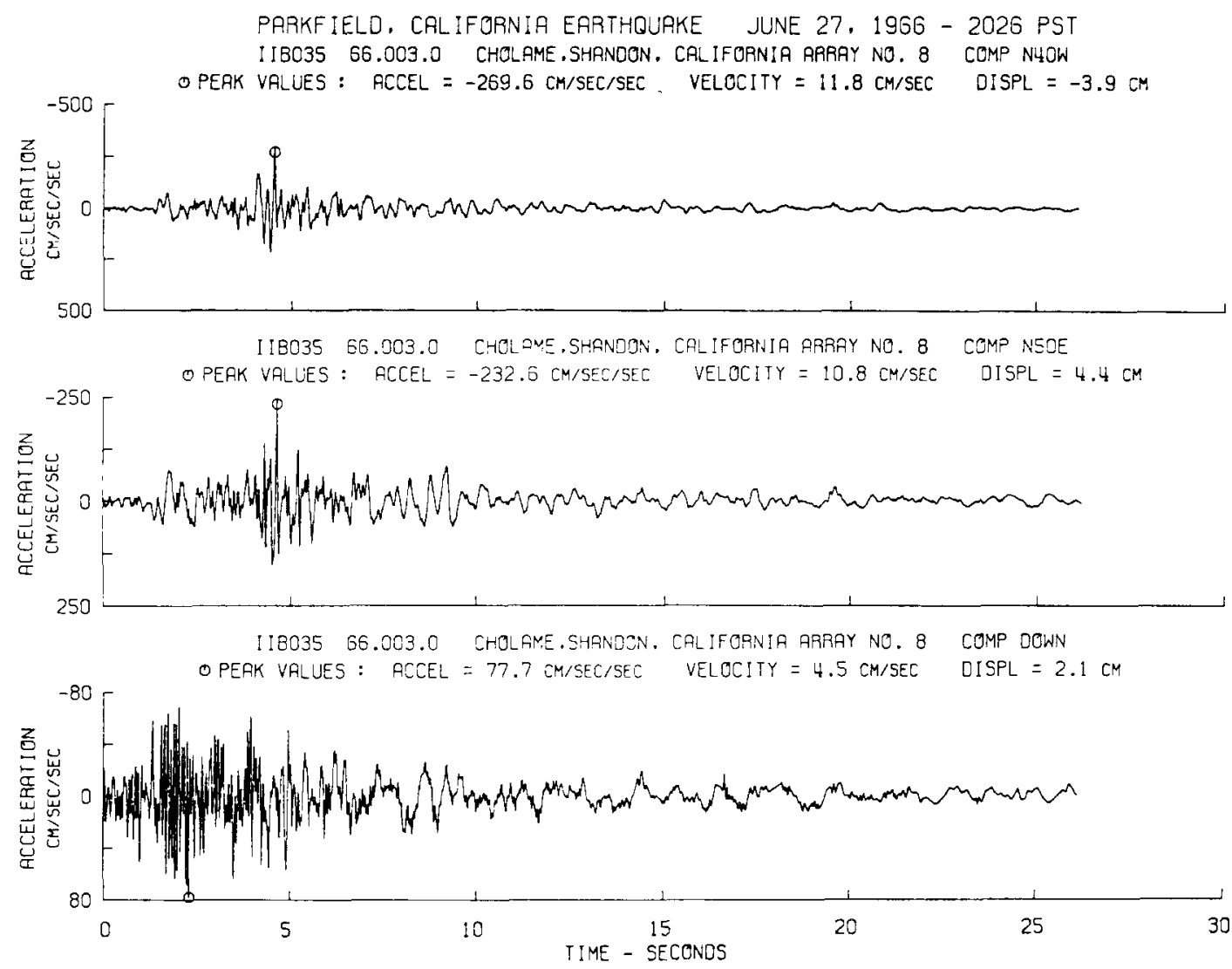

FIG. 5. Accelerograms from the Parkfield earthquake recorded at station $8, \Delta=9 \mathrm{~km}$ (from Hudson et $a l ., 1969-1976)$.

primarily interested in the comparison of the observed and simulated accelerograms.

Figure 5 reproduces the three-component accelerogram recorded by station 8 , $\Delta=9 \mathrm{~km}$, for the Parkfield earthquake (Hudson, et al., 1968-1976). Because the accelerations recorded on the horizontal components are about a factor of 2 to 3 larger than the vertical component, for stations 2, 5, 8, and Temblor, the simulation has been restricted to the two horizontal components. Figure 6 shows an example of the simulation for the geometry corresponding to station 8 . Note that the peak accelerations and the duration of strong shaking for the observed and simulated accelerograms are in good agreement. Figure 7 shows the comparison of the peak acceleration for both the simulated and observed accelerograms. Both the absolute level of the accelerations and the decay with distance for the simulation is in good 
agreement with the data. The one exception is station 12 which is depressed by a factor of 2 to 3 . The ratio of the horizontal-to-vertical peak accelerations for this station is about 1 , whereas the ratio for the other four stations is 2 to 3 . This comparison suggests that the amplitude of the horizontal components is somewhat depressed at this station. Furthermore, Kanamori and Jennings (1978) have calculated $M_{L}$ from the digitized strong-motion records for the Parkfield stations. Assuming the distance correction for $M_{L}$ to be the nearest point on the fault, their average for all five stations is $M_{L}(S-M)=5.80 \pm 0.3$. The same calculation for station 12 yields the lowest value, $M_{L}(S-M)=5.45$. This low value is equivalent to an amplitude difference of 2.5. This comparison suggests that over a broad range of frequencies, the observed horizontal accelerograms at station 12 are anomalously attenuated.

This simulation should also accurately represent some of the longer period characteristics of the earthquake source. As a check, we have computed $M_{L}$ for each simulation. The average for the Parkfield geometry is $M_{L}=5.46 \pm 0.2$. This is in

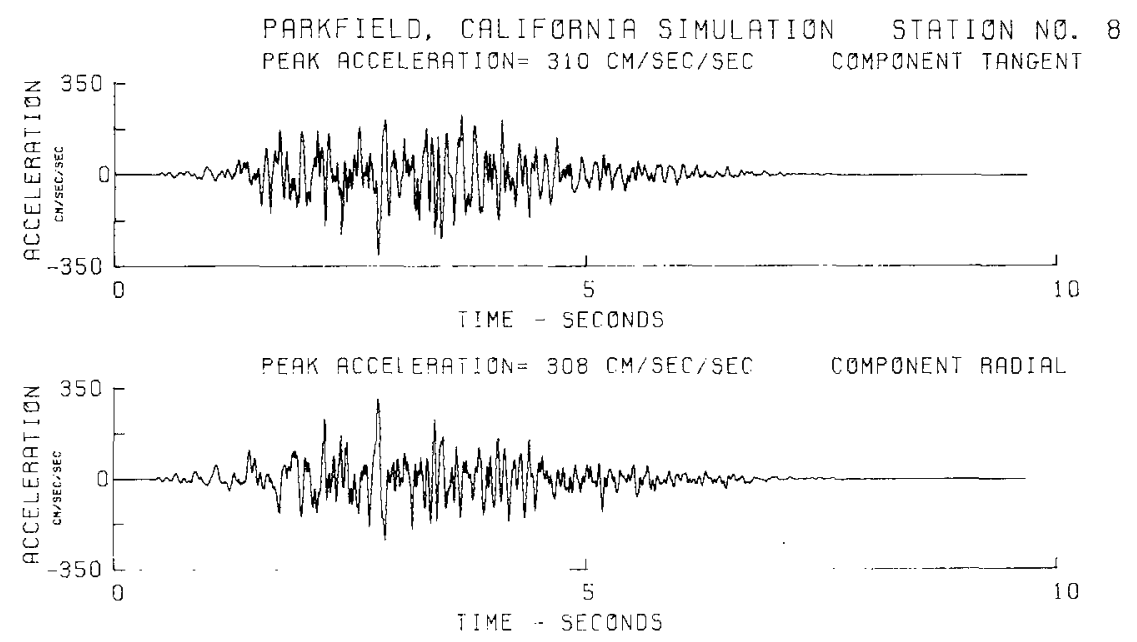

FIG. 6. Simulated accelerograms for the Parkfield earthquake for station 8 .

good agreement with Berkeley (5.5) and Pasadena (5.8). However, as compared with the Kanamori and Jennings (1978) $M_{L}$ value of $5.80 \pm 0.3$ derived from the strongmotion records, the long-period component of the simulation is too low. In part, this may result from an artifact in the initial processing of the accelerograms used in the simulation. The records were high-pass filtered with the corner of the filter located at 1 sec. Hence, periods longer than $1 \mathrm{sec}$ are not adequately represented in this simulation.

\section{SimUlation FOR MAGNiTUde 5.5, 6.5, AND 7.0}

Following the same procedure as discussed for the Parkfield event, we have modeled three additional strike-slip earthquakes. An example of the magnitude 6.5 simulation is shown in Figure 3 . The fault geometry and moment have been adopted from the April 9, 1968 Borrego Mountain earthquake $\left(M_{S}=6.7, m_{b}=6.1, M_{\text {Pasadena }}\right.$ $=6.4, M_{L}$ [from strong-motion records, Kanamori and Jennings (1978)] $=6.9$. Following the study by Burdick and Mellman (1976) we have used a moment of 1 $\times 10^{26}$ dyne-cm, and a rupture area of $40 \times 12 \mathrm{~km}$. Simulations were computed for five horizontal distances from the fault: 5, 10, 15, 20, and $25 \mathrm{~km}$. For each distance, 
four fault-rupture stations geometries were modeled. In all simulations, the stations were located along a line perpendicular to the fault. In the first two, the stations were located at the end of the fault and the rupture was unilateral from each end. In the second pair of simulations the stations were located in the center of the fault and rupture was first bilateral, initiating at the center, and then unilateral. In all cases, the depth to the center of the fault was fixed at $6.5 \mathrm{~km}$. For each distance and fault geometry, peak accelerations were recorded from the simulated radial and transverse components. The final average peak acceleration at each distance, presented in Figure 8, is the average of both components for the four simulated geometries.

The second earthquake simulated was an $M_{S}=7.0$. The moment used was $2.6 \times$ $10^{26}$ and the fault dimensions were $60 \times 13 \mathrm{~km}$. Displacement at all points along the fault was 50 per cent larger than for the magnitude 6.5 simulation. These values have been selected from the worldwide data set discussed by Kanamori and

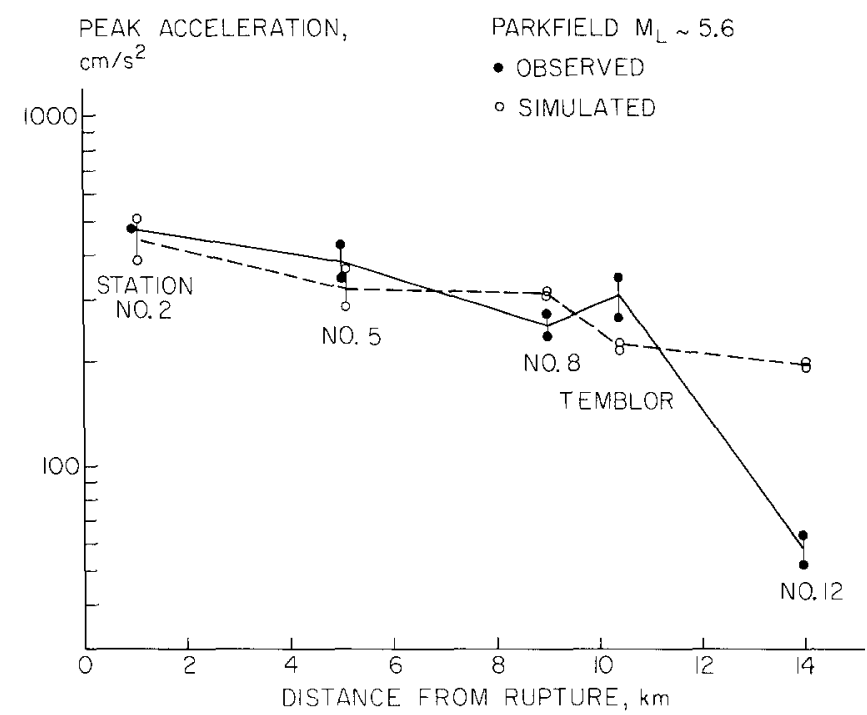

FIG. 7. Comparison between observed and simulated peak accelerograms for the Parkfield earthquake.

Anderson (1975). As discussed above, the same station geometries, fault rupture orientation, and averaging of the peak acceleration were used.

As a final example, a magnitude 5.5 earthquake was simulated. The moment was adjusted to $2.7 \times 10^{24}$ dyne-cm in agreement with the Hartzell and Brune (1977) relation $\left(\log M_{0}=15+1.7 M_{L}\right)$. The fault dimensions of 6 by $6 \mathrm{~km}$ were selected on the basis of Utsu and Seki, $1954(\log$ area $=1.02 M-4.01)$. The average peak accelerations are shown in Figure 8. In order to match the moment, the simulation of this event requires only nine Horse Canyon events, whereas the $M=6.5$ to 7.0 earthquakes required the summation of 300 to 1,000. Because the large number of accelerograms superimposed in simulation of the larger events, noise in the data has only a minor effect in the overall summation and final average accelerations. For the $M_{L}=5.5$ simulation, the noise in the data is not so effectively smoothed. Because of the small source area, only two station-fault geometries were simulated. In both cases the line of stations was centered on the fault. Rupture was first bilateral and then unilateral. 
Comparison of Simulation with the Extrapolation of Peak Acceleration DATA FOR A $M=6.5$ EARTHQUAKE

Simulations for magnitude 5.5, 6.5, and 7.0 earthquakes and the associated average peak accelerations have been discussed in the previous sections. Within this section we compare the slope and position of the average peak accelerations with data from

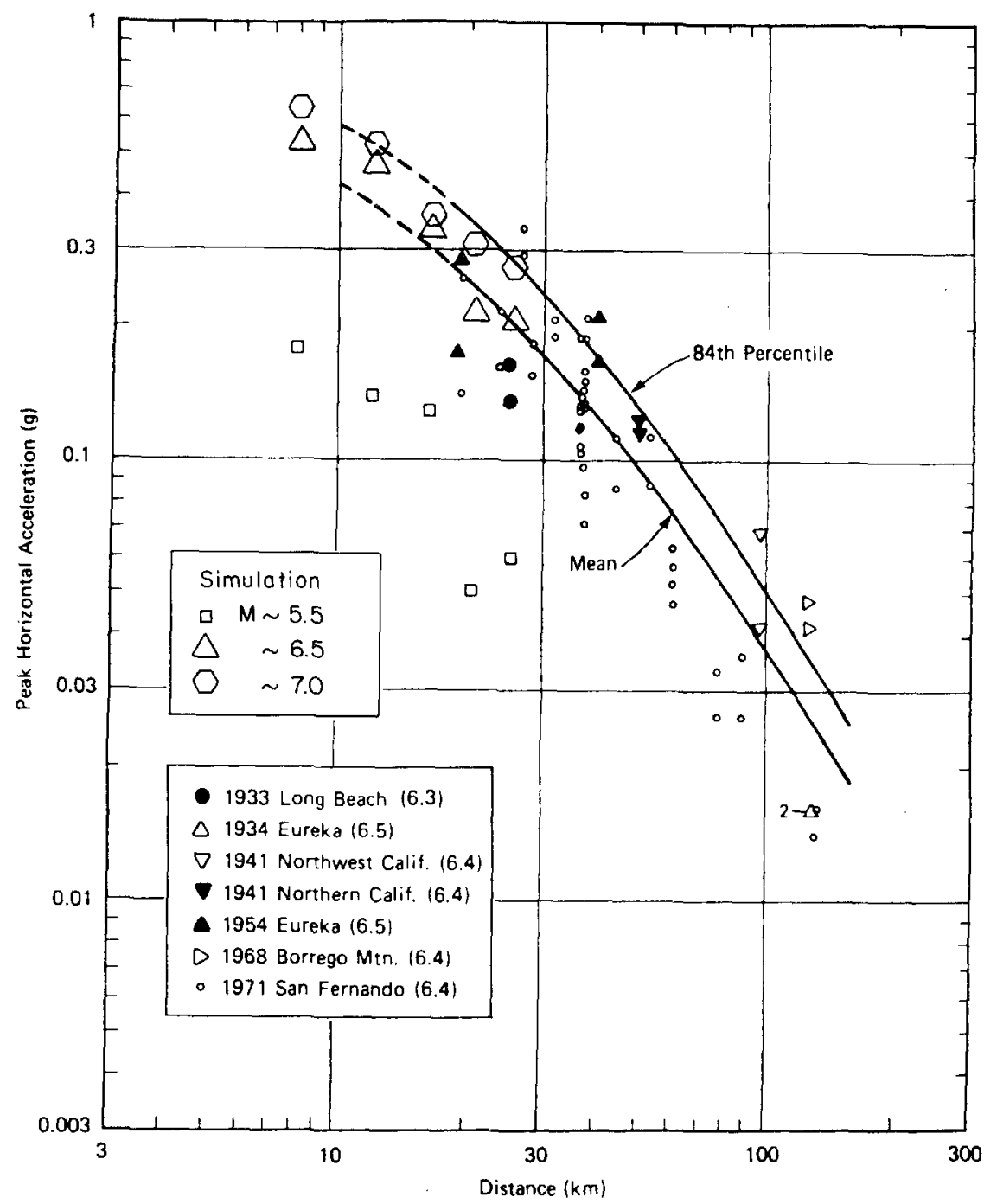

FIG. 8. Comparison of the simulation for peak acceleration, $M=5.5,6.5$, and 7.0 , with data from $M$ $\sim 6.5$ earthquakes. The regression curve through the data is P. A. $=161(R+20)^{-1.75}$. The data and the regression curve are discussed by Woodward-Clyde Consultants (1979).

seven other magnitude $\sim 6.5$ earthquakes. Because of the uncertainty introduced by the dynamic similarity condition, or equivalently, the rupture velocity, the absolute level was adjusted so that the point $M=6.5, \Delta=25 \mathrm{~km}(R=25.8 \mathrm{~km}$ to the center of the fault) fits the regression through the observed data (data and regression are discussed by Woodward-Clyde Consultants, 1979). However, as seen in the Parkfield simulation, the absolute level of the average peak accelerations are in good agreement with the data. Only a 7 per cent correction was required to bring the absolute level of the simulation into agreement with the data at $25 \mathrm{~km}$. The comparison 
between the extrapolated regression curve and the adjusted accelerations, for all three magnitudes, is shown in Figure 8 . Note that the average attenuation versus distance slope for the $M_{L}=5.5$ event $(R=8.2$ to $25.8 \mathrm{~km})$ is quite similar to the slope for the observed $M=6.5$ data at distances of about $100 \mathrm{~km}$. As the magnitude goes up, both the level of the peak acceleration increases and the attenuation versus distance relationship flattens. Provided each point on the fault radiates energy over the time period $\tau_{c}$, the physics of this effect is slightly analogous to other phenomena where the decay of the field with distance for a point source changes, in the limit, to a distance independent field as the point expands into a plane.

The results of this simulation study require a functional form of the effective attenuation versus distance curves, for strike-slip earthquakes, that allows for a significant decrease in the slope of the curve at smaller epicentral distances. The study further shows that for general use, the form of this function [e.g., $(R+C)^{-x}$ ] should incorporate a magnitude dependence $[C=F(M)]$.

\section{ACKNOWLEDGMENTS}

This project benefited from frequent discussions with Robert S. Hart and Woody Savage. Steve Hartzell kindly provided the digitized Horse Canyon accelerograms. The authors thank Bill Joyner and Dave Boore for critically reviewing the manuscript. The research was supported under contract with Woodward-Clyde Consultants for Southern California Edison. Sierra Geophysics Report SGI-R-007.

\section{REFERENCES}

Aki, K. (1972). Scaling law of earthquake source time-function, Geophys. J. 31, 3-25.

Brune, J. (1970). Tectonic strain and the spectra of seismic shear waves from earthquakes, $J$. Geophys. Res. 75, 4997-5009.

Burdick, L. J. (1977). Broad-band seismic studies of body waves, Ph.D. Thesis, California Institute of Technology, 151.

Burdick, L. J. and G. R. Mellman (1976). Inversion of the body waves from the Borrego Mountain earthquake to the source mechanism, Bull. Seism. Soc. Am. 66, 1485-1499.

Eaton, J. P., M. E. O'Neill, and J. N. Murdock (1970). Aftershocks of the 1966 Parkfield-Cholame, California earthquake: A detailed study, Bull. Seism. Soc. Am. 60, 1151-1197.

Hartzell, S. H. and J. N. Brune (1977). Source parameters for the January, 1976 Brawley-Imperial Valley earthquake swarm, Pageoph 115, 333-355.

Hartzell, S. H. (1978a). Earthquake aftershocks as Green's functions, Geophys. Res. Letters 5, 1-4.

Hartzell, S. H. (1978b). Interpretation of earthquake strong ground motion implications for earthquake mechanism, Ph.D. Dissertation, University of California San Diego, p. 269.

Heaton, T. H. and D. V. Helmberger (1978). Predictability of strong ground motion in the Imperial Valley: Modeling the $M=4.9$, November 4, 1976 Brawley earthquake, Bull. Seism. Soc. Am. 68, 3148.

Helmberger, D. V. and S. D. Malone (1975). Modeling local earthquakes as shear dislocations in a layered half space, J. Geophys. Res. 80, 4881-4888.

Helmberger, D. V. and L. R. Johnson (1977). Source pararneters of moderate size earthquakes and the importance of receiver crustal structure in interpreting observations of local earthquakes, Bull. Seism. Soc. Am. 67, 301-313.

Hudson, D. E., M. D. Trifunac, and A. G. Brady (1969 to 1976). Analysis of strong-motion accelerograms, V. I, Parts A-Y, V. II, Parts A-Y, V. III, Parts A-Y, V. IV, Parts A-Y, Index V. (EERL Rep. 76-02), Earthquake Engineering Research Laboratory, California Institute of Technology, Pasadena.

Johnson, L. R. and T. V. McEvilly (1974). Near-field observations and source parameters of central California earthquakes, Bull. Seism. Soc. Am. 64, 1855-1886.

Kanamori, H. and D. L. Anderson (1975). Theoretical basis of some empirical relationships in seismology, Bull. Seism. Soc. Am. 65, 1073-1095.

Kanamori, H. (1976). August 2, 1975 Horse-Canyon earthquake, in U.S. Geol. Surv., Open-File Rept. on Earthquake Prediction Studies in Southern California, Oct. 1975-Sept. 1976.

Kanamori, H. (1978). Application of earthquake mechanism studies to prediction of long-period ground motion related problems, U.S. Geol. Surv. Final Technical Rept. Contract 14-08-0001-16776.

Kanamori, H. and P. C. Jennings (1978). Determination of local magnitude, $M_{L}$, from strong-motion accelerograms. Bull. Seism. Soc. Am. 68, 471-485. 
Langston, C. A. (1978). The February 9, 1971 San Fernando earthquake: A study of source finiteness in teleseismic body waves, Bull. Seism. Soc. Am. 68, 1-30.

Scholz, C. H., M. Wyss, and S. W. Smith (1969). Seismic and aseismic slip on the San Andreas fault, $J$. Geophys. Res, 74, 2049-2069.

Trifunac, M. D. and F. G. Udwadia (1974). Parkfield, California earthquake of June 27, 1966: A threedimensional moving dislocation, Bull. Seism. Soc. Am. 64, 511-533.

Tsai, Y. B. and K. Aki (1969). Simultaneous determination of the seismic moment and attenuation of seismic surface waves, Bull. Seism. Soc. Am. 59, 275-287.

Utsu, T. and A. Seki (1954). A relation between the area of aftershock region and the energy of main shock, J. Seism. Soc. Japan 7, 233-240.

Woodward-Clyde Consultants (1979). Report of the evaluation of maximum earthquake and site ground motion parameters associated with the offshore zone of deformation, San Onofre Nuclear Generating Station.

SIERRA GEOPHYSICS, INC. 150 North Santa Anita Avenue ArCadia, California 91006 (D.M.H.)
SEISMOLOGICAL LABORATORY

California Institute of Technology

Pasadena, California 91125 (D.V.H.)

Manuscript received August 21, 1979 